\title{
Recognizing the role of occupational therapists within the primary health care model
}

\author{
Chelsea Gordon
}

\section{University of Alberta}

\section{Introduction}

Primary Health Care (PHC) is a social approach to health that identifies a broad spectrum of care as essential to achieving "better health for all." ${ }^{1}$ PHC emphasizes the integration of primary care (considered the first point of contact that individuals have to a health worker, like a general physician) with secondary services, which promote health and prevent or manage chronic illness and/or dysfunction (like smoking cessation programs or housing initiatives for the homeless). Simply stated, PHC is a set of values to guide health practices, using proactive/preventative, and reactive/ remedial approaches to the whole health of communities, to accomplish better health outcomes for all Canadians.

Occupational therapists (OTs) utilize a holistic biopsychosocial approach to health which compliments PHC values. The World Health Organization (WHO) and Health Canada have identified social factors as critical determinants of health. ${ }^{1,2}$ These are often referred to as the social determinants of health, and include factors such as income, housing, education and a person's environment. ${ }^{3}$ OTs in Canada are trained at a Master's level to analyze the physical, social, institutional, cultural, attitudinal, and legislative domains of the environment with a focus on how occupation, defined as any activity of daily living, contributes to health and wellness for individuals and populations. ${ }^{4,5}$ Like PHC, OT values a multidisciplinary approach to working with individuals, communities, and populations, from a client-centred perspective to achieve better health. These similarities align OTs to be leaders within the PHC reform in Canada.

\section{A Challenge to the Implementation of PHC}

Primary health care finds strength in a multidisciplinary team-based approach to increasing access to health services, responding to the needs of specific communities, and integrating health services to address health equity gaps for Canada's diverse communities, ${ }^{1,2}$ A challenge to the implementation of $\mathrm{PHC}$ is providing tailored health care to each of Canada's many diverse communities (ex. rural or remote areas) and populations (ex. individuals living with addictions). Canada is working to reform health care services and it is up to service providers, including OTs and policy makers, to evaluate how restrictions to social determinants of healthcare are impacting health and to develop primary and secondary health services designed to fit the unique needs of individuals, communities, and populations.

\section{Shared Competencies: OTs and PHC Teams}

Occupational therapists typically provide services at the patient-level; however, their unique approach to health enables OTs to evaluate and identify health issues from a population-level as well. The OT's ability to understand how manyenvironmental domainsimpact health is a valuable tool that should be utilized in the PHC reform. The Pan American Health Organization (PAHO) outlined competencies that are required for the successful transition to $\mathrm{PHC} .{ }^{6}$ For example, providing "Comprehensive and Integrated Care" is defined by PAHO as the second core competency, and includes training to accurately identify the needs of individuals and families, the capacity to respond to health problems within communities, knowledge of other health services, and promoting "health self-care". ${ }^{6}$ OTs possess many of these competencies. They are highly skilled in critically analyzing the interplay between the person, environment, and occupation to identify and respond to areas of need. ${ }^{7}$ Furthermore, they are inter-professionally educated, ${ }^{8}$ and always strive to support a client's participation in their own occupations and health care needs. ${ }^{9}$

A framework for OTs establishing an inter-professional practice within the PHC model has been designed in collaboration with the Canadian Association of Occupational Therapists (CAOT). ${ }^{10}$ The tool further emphasizes the fit of $\downarrow$ 
OTs in PHC, highlighting the importance of utilizing best practices at a patient and population level. ${ }^{10}$ The PHC skills outlined by PAHO, and the tool provided by the CAOT demonstrate that OTs are well positioned to be leaders on PHC teams, and to have an important voice at the policy level of the PHC reform in Canada.

\section{Conclusions: Advancing the Reform and Improving Health}

Canada's health care reform toward integrated PHC, tailored to the idiosyncrasies of the country's populations, requires the effort of healthcare teams from the front line and up to the policy and litigation levels. Serving the diversity of communities found across and within the nation is one challenge being met by the reform. OTs are health professionals who are governed by the values, and equipped with skills, which can promote the PHC reform. Involving OTs from the beginning, with the conception and development of new community initiatives, organizing and delivering wellness promoting services, providing input and advocating at a policy level, and implementing their own programs or practices, for communities based on specific identified needs will help progress the PHC reform. Moving forward, it is imperative that OTs recognize their contributions to PHC so that they may advance their professional presence working with and for Canada's unique communities and populations to improve health for all.

\section{References}

1. World Health Organization. Primary health care [internet website]. 2014 [cited 2014 Feb 5]. Available from: http://www.who.int/topics/primary health care/en/

2. Health Canada. Primary health care [internet website]. 2012 [cited 2014 Jan 30]. Available from: http://www.hc-sc.gc.ca/hcs-sss/prim/about-aproposeng.php\#a3

3. Mikkonen J, Raphael D. Social determinants of health: The Canadian facts. Toronto: York University School of Health Policy and Management; 2010. Available from: http://www.thecanadianfacts.org

4. Canadian Association of Occupational Therapy. Professional practice: Code of ethics [internet website]. 2014 [cited 2014 Feb 5] Available from: http:// www.caot.ca/default.asp?pageid=35

5. World Federation of Occupational Therapists. Fundamental Beliefs: Statement on occupational therapy [internet website]. 2011 [cited 2014 Feb 5]. Available from: http://www.wfot.org/AboutUs/FundamentalBeliefs.aspx

6. Pan American Health Organization. Primary health care-based health systems: Strategies for the development of primary health care teams. Washington, DC: PAHO; 2009. Available from: http://www2. paho.org/hq/ dmdocuments/2010/PHC-Strategies-Development-PHC-Teams.pdf

7. Law M, Cooper B, Strong S, Stewart D, Rigby P. The Person-EnvironmentOccupation Model: A transactive approach to occupational performance. Canadian Journal of Occupational Therapy. 1996; 63(1):9-23.

8. Canadian Association of Occupational Therapy. About CAOT [internet website]. 2014 [cited 2014 Feb 5]. Available from: http://www.caot.ca/ default.asp?pageid $=2$

9. Canadian Association of Occupational Therapy. Occupational therapy values and beliefs [internet website]. 2014 [cited 2014 Feb 5]. Available from: https://www.caot.ca/default.asp?pageid=3619

10. McColl, M.A. Occupational therapy in primary health care: Assembling the pieces, a framework to build your practice in primary health care [internet website]. 2008 [cited 2014 April 12]. Available from: http://www.caot.ca/ pdfs/primary\%20healthcare.pdf

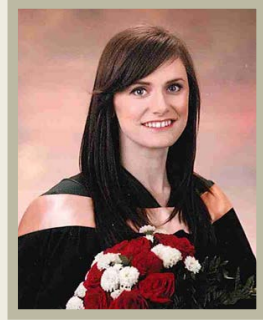

\section{Chelsea Gordon}

Chelsea Gordon is currently finishing her Master of Science in Occupational Therapy at the University of Alberta and has a Bachelor of Arts in Psychology from the University of Saskatchewan. Her research interests include occupational therapy practice in end-of-life and mental health. 